\title{
LITERATURA JUVENIL CONTEMPORÂNEA: REPRESENTAÇÕES DE EXPERIÊNCIAS HOMOSSEXUAIS NA ESCOLA
}

\author{
LITERATURA JUVENIL CONTEMPORÁNEA: REPRESENTACIONES DE \\ EXPERIENCIAS HOMOSEXUALES \\ EN LA ESCUELA
}

\section{YOUTH CONTEMPORANY LITERATURE: REPRESENTATIONS OF HOMOSEXUAL EXPERIENCES IN SCHOOL}

\author{
Caroline Amaral AMARAL ${ }^{1}$ \\ Paula Regina Costa RIBEIRO ${ }^{2}$
}

RESUMO: Este artigo tem por finalidade discutir os significados que são (re)produzidos em livros juvenis contemporâneos acerca da experiência homossexual masculina no espaço da escola. Utiliza-se da noção de experiência a partir de Jorge Larrosa. O corpus de análise é constituído por três livros de literatura juvenil LGBTI. Para as análises, utilizamos os princípios de exterioridade, reflexividade e subjetividade, segundo Larrosa. É possível observar que as instituições escolares desempenham um papel importante no que concerne à subjetivação das personagens, se mostrando uma instância (re)produtora de normas; é representada como lugar que legitima discursos homofóbicos, mas também como lugar de luta e promoção das diferenças, instituição que interpela a forma como as personagens atribuem sentido à experiência homossexual.

PALAVRAS-CHAVE: Literatura juvenil. Artefato cultural. Experiência. Homossexualidade masculina. Escola.

RESUMEN: Este artículo tiene como finalidad discutir los significados (re)producidos en libros juveniles contemporáneos sobre la experiencia homosexual masculina en el espacio de la escuela. Se parte de la noción de experiencia de Jorge Larrosa. O corpus de análisis está constituido por tres libros de literatura juvenil LGBTI. Para los análisis, utilizamos los principios de exterioridad, reflexividad y subjetividad de acuerdo a Larrosa. Es posible observar que las instituciones escolares desempeñan un papel importante en lo que concierne a la subjetivación de los personajes mostrándose una instancia (re)productora

\footnotetext{
${ }^{1}$ Universidade Federal do Rio Grande (FURG), Rio Grande - RS - Brasil. Doutoranda em andamento no Programa de Pós-Graduação em Educação em Ciências: Quimica da Vida e Saúde e Graduanda do curso de Psicologia também pela FURG. Integrante do Grupo de Pesquisa Sexualidade e Escola. ORCID: <http://orcid.org/0000-0003-4851-8389>. E-mail: carolinefurgletras@ gmail.com

${ }^{2}$ Universidade Federal do Rio Grande (FURG), Rio Grande - RS - Brasil. Professora Titular do Instituto de Educação e professora dos Programas de Pós-Graduação: Educação em Ciências (Associação Ampla FURG/UFRGS/UFSM) e Educação Ambiental da Universidade Federal do Rio Grande - FURG. Tem experiência nas áreas de Ensino de Ciências, Biologia e Educação para a Sexualidade. É líder do Grupo de Pesquisa Sexualidade e Escola - GESE, atuando principalmente nos seguintes temas: corpos, gêneros e sexualidades. Bolsista produtividade 1C do CNPq. ORCID: 〈http://orcid.org/0000-0001-7798-996X>. Email: pribeiro.furg@gmail.com
}

RIAEE - Revista Ibero-Americana de Estudos em Educação, Araraquara, v. 13, n. 4, p. 1726-1741, out./dez., 2018. 
de normas; es representada como lugar que legitima discursos homofóbicos, pero también como lugar de lucha y promoción de las diferencias, institución que interpela la forma en que los personajes atribuyen sentido a la experiencia homosexual.

PALABRAS CLAVE: Literatura juvenil. Artefacto cultural. Experiencia. Homosexualidad masculina. Escuela.

ABSTRACT: This article aims to discuss the meanings (re)produced in contemporary youth books about male homosexual experience in school space. We use the Jorge Larrosa's notion of experience. The corpus of analysis consists in three books of youth LGBTI literature. For the analysis, we use the principles of exteriority, reflexivity and subjectivity according to Larrosa. It's possible to observe that the school institutions play an important role in terms of the subjectivation of the characters if they show a (re)producing instance of norms; it is represented as a place that legitimizes homophobic discourses, but also as a place of fight and raise of differences, an institution that challenges the way in which characters attribute meaning to the homosexual experience.

KEYWORDS: Youth literature. Cultural artifact. Experience. Male homosexuality. School.

\title{
Introdução
}

\begin{abstract}
Um trabalho insano! Moderar, animar, corrigir esta massa de caracteres, onde começa a ferver o fermento das inclinações; encontrar e encaminhar a natureza na época dos violentos ímpetos; amordaçar excessivos ardores; retemperar o ânimo dos que se dão por vencidos precocemente; espreitar, adivinhar os temperamentos; prevenir a corrupção; desiludir as aparências sedutoras do mal; aproveitar os alvoroços do sangue para os nobres ensinamentos; prevenir a depravação dos inocentes; espiar os sítios obscuros; fiscalizar as amizades; (Trecho da obra $O$ Ateneu, de Raul Pompéia, 1888).
\end{abstract}

Frente ao trecho da obra de Raul Pompéia, vemos que a instituição escolar é representada como espaço onde os sujeitos deveriam ser moderados e corrigidos, lugar onde os ardores excessivos deveriam ser amordaçados. Mesmo estando a uma considerável distância cronológica da obra percebe-se que a escola, em algumas obras contemporâneas, permanece sendo representada como uma instância reguladora de sujeitos. Consequentemente, as instituições escolares por vezes são vistas como fortemente 
empenhadas na reafirmação e garantia do êxito dos processos de heterossexualização compulsória e de incorporação das normas de gênero (BUTLER, 2014), colocando sob vigilância os corpos de todos(as) (JUNQUEIRA, 2013).

Contudo, sabe-se que paralelo às continuidades também podem existir algumas rupturas, pois não há $a$ verdade que represente a instituição escolar, mas as representações - que não dizem respeito a uma "recriação" fiel do que existe, mas produções discursivamente, em meio a relações de poder (COSTA, 2003) - sobre essa são constituídas de diversos significados que a ela atribuímos. Haja vista que a verdade é construção social, cultural e história; é resultante e produzida por meio de efeitos de poder, que por sua vez produzem efeitos que regulam e organizam o mundo (FOUCAULT, 2015). Nesse sentido, este artigo tem por finalidade discutir os significados que são (re)produzidos em três livros juvenis contemporâneos acerca da experiência homossexual masculina no espaço da escola.

A instância escolar é tomada neste artigo como eixo norteador da análise, porque é citada nos livros de forma recorrente. Entende-se que ela se constitui como instância privilegiada de análise, pois é um espaço permeado por diferenças de corpos, gêneros e sexualidades (LOURO, 2000). Entende-se que "a sexualidade está no espaço escolar porque faz parte dos sujeitos o tempo todo. Ninguém se despe da sexualidade ou a deixa em casa como um acessório do qual pode se despojar" (MISKOLCI, 2014, p. 79). Nessa esteira, faz-se o questionamento: de que maneira estes livros juvenis representam a experiência homossexual no espaço da escola?

\section{Literatura e homossexualidade: uma relação contemporânea?}

Sabe-se que a literatura em suas variadas manifestações aborda o relacionamento entre pessoas de mesmo gênero e que isso não diz respeito a produções contemporâneas apenas. No entanto, o termo homossexualidade nem sempre foi utilizado no meio literário, tendo em vista sua recente emergência. Daniel Barbo (2013) aponta que por volta da década de 1860 emergiram algumas nomenclaturas que procuravam nomear desejos e comportamentos entre pessoas do mesmo gênero, especialmente desejos entre homens. Para o autor, o movimento era "de classificar tipos numa nebulosa de inversões sexuais" (BARBO, 2013, p. 12). Ao retomar algumas produções literárias, é possível se deparar com termos como sodomia, homoerotismo, pederasta, urning, dentre outras expressões. 
Muitas dessas nomenclaturas, usadas para caracterizar personagens, carregavam com elas um caráter discriminatório e patologizante (BARBO, 2013), fatores esses que contribuíram para o abandono - nem sempre total - de seus usos. Porém, cabe ressalva de que os termos listados não são equivalentes ao que chamamos de homossexualidade hoje.

De acordo com Louro (2013, p. 29), "a homossexualidade e o sujeito homossexual são invenções do século XIX”, sendo o termo uma produção específica do mundo ocidental. Após a sua retirada da lista de transtornos mentais ${ }^{3}$, deixando de ser homossexualismo para ser nomeada como homossexualidade.

Como constituinte das culturas em que está imersa, a literatura buscou - e ainda busca - falar sobre a homossexualidade, seja almejando promover o respeito ou mesmo de forma caricaturada fazendo com que certos estereótipos reverberem, disseminando discursos discriminatórios. De uma maneira ou outra, a homossexualidade constituiu o universo da literatura - e por ela é constituída - durante muito tempo, não sendo temática exclusiva da contemporaneidade. Antônio Silva e Carlos Eduardo Fernandes (2014) afirmam que a literatura homoerótica (assim classificada por eles), está presente na literatura antes mesmo do século XX.

O que motiva a escrita deste artigo é o fato de que atualmente o assunto vem sendo tratado de forma um tanto mais "aberta" e paulatinamente vem se direcionando ao público juvenil, promovendo fissuras nos discursos que veem a discussão sobre a homossexualidade como algo proibido à jovem leitora e ao jovem leitor.

Compreende-se que este movimento na literatura juvenil está em consonância com diversas lutas sociais, visto que a arte literária se desdobra em diversas faces, evidenciando seu caráter político e artístico. A literatura se expressa por meio de palavras, imagens, sons e rimas que também produzem verdades que são construídas na e pela sociedade. Segundo Beatriz Resende (2011), pensar a respeito da literatura contemporânea é refletir sobre estas outras formas de produzir narrativas literárias, assim como pesquisas de Daniela Ripoll e Rosa Maria Silveira (2016), Rodrigues Júnior (2007), Antônio Silva e Carlos Fernandes (2011), dentre outros/as pesquisadores/as que têm atentado para a pluralidade dos gêneros literários.

\section{Afinidades teóricas}

${ }^{3}$ Retirada da lista de doenças pela Organização Mundial da Saúde (OMS) no dia 17 de maio de 1990. 
Pautado nos Estudos Culturais em contexto pós-estruturalista, este trabalho toma a literatura juvenil como um artefato cultural resultante das relações sociais, que contêm pedagogias, ao mesmo tempo que constroem e produzem significados (SILVA, 2010). Sendo assim, não há espaço para a classificação dos livros enquanto "boa literatura", "má literatura". Os livros analisados são artefatos culturais que produzem significados sobre modos de ser gay dentro do contexto escolar (Id., 2010). A literatura juvenil também é considerada uma forma de naturalização de verdades. Os livros em questão produzem saberes sobre a homossexualidade masculina através de suas pedagogias culturais.

Aprendemos sobre nós mesmos e sobre o mundo a partir daquilo que vivemos nos mais diversos lugares, através das mais variadas maneiras que nos colocamos e somos colocados/as no mundo. Ao entender que a linguagem não somente descreve, mas também nos constitui (COSTA, 2003), corrobora-se que as palavras não são meramente signos linguísticos, elas nos produzem, ensinam e educam. (LARROSA, 2002).

Pensar a homossexualidade masculina como uma experiência permite colocar em suspenso as verdades naturalizadas que engessam a sexualidade como inata e imutável (FERRARI, 2014). Para isso, parte-se da noção de experiência proposta por Larrosa (2002; 2011; 2015).

Por experiência, entende-se a relação entre uma pessoa e aquilo que lhe acontece, é por meio dela que podemos dar sentido e significado àquilo que nos ocorre. Por conseguinte, a noção de experiência está ligada àquilo que a pessoa é - ou mesmo com aquilo que pensa ser -, está imbricada com a subjetividade do sujeito, pois "a experiência é o que nos passa, o que nos acontece, o que nos toca. Não o que se passa, não o que acontece, ou o que toca". (LARROSA, 2002, p. 21). No entanto, a noção de experiência não se esgota nisso, tendo em vista que "não é uma realidade, uma coisa, um fato, não é fácil de definir nem de identificar, não pode ser objetivada, não pode ser produzida. E tampouco é um conceito, uma ideia clara e distinta" (LARROSA, 2015, p. 10). Sendo assim, a noção de experiência será utilizada para tecer análises acerca das maneiras como a homossexualidade é tomada na instância social escola representada nos livros, e analisar de que maneira as personagens dão sentido ao que são a partir daquilo que lhes acontece.

Nesse contexto, entende-se que não existe $a$ experiência homossexual, mas sim experiências, porque o que nos acontece pode ser igual, mas o modo como atribuímos significado ao que nos acontece, a maneira como lhe atribuímos sentido é individual (LARROSA, 2002). 
Para as análises, serão utilizados alguns apontamentos com base nos princípios de exterioridade, reflexividade e subjetividade segundo Larrosa (2011).

O princípio da exterioridade diz respeito a algo que não faz parte do sujeito, mas que ocorre devido ao contexto em que se está inserido. $\mathrm{O}$ que nos traz ao princípio da alteridade, tendo em vista que a experiência é algo do outro, que não é nosso. Por sua vez, o princípio da exterioridade tem relação com aquilo que nos cerca, não com aquilo que somos, pois:

[...] não há experiência, portanto, sem a aparição de alguém, ou de algo, ou de um isso, de um acontecimento em definitivo, que é exterior a mim, estrangeiro a mim, estranho a mim, que está fora de mim mesmo, que não pertence ao meu lugar, que não está no lugar que eu lhe dou, que está fora de lugar. (LARROSA, 2011, p. 5).

Entende-se como princípio da reflexividade parte da experiência como um movimento de ida e de volta, de modo que se configura como um encontro da pessoa com aquilo que lhe ocorreu, assim, a pessoa vai ao encontro daquilo que aconteceu e volta para si, para dentro de si. É algo que lhe tocou, afetou, fazendo com que este movimento de ida e de volta cause efeitos. Desse modo, esse princípio parte do pressuposto de que ela produz efeitos naquele/a que lhe passa,

[...] porque o lugar da experiência é o sujeito ou, dito de outro modo, que a experiência é sempre subjetiva. Contudo, se trata de um sujeito que é capaz de deixar que algo lhe passe, quer dizer, que algo passe a suas palavras, a suas ideais, a seus sentimentos, a suas representações, etc. (LARROSA, 2011, p. 7).

O princípio da subjetividade age no sujeito, naquele/a que se deixa tocar pelo que aconteceu, aquela/e que a experiência interpela suas palavras, seu modo de entender a si mesmo, suas representações e seus acontecimentos. Nas palavras de Larrosa (2011, p. 7 , grifo nosso), "se lhe chamo "princípio de reflexividade" é porque esse me de 'o que me passa' é um pronome reflexivo".

Sendo assim, o sujeito da experiência é aquele/a que está exposto, aberto (GARCIA, 2015), é aquela/e que se deixa tocar por aquilo que lhe acontece, e, aquilo que lhe acontece faz com que atribua sentido a forma como vê e se relaciona consigo e com mundo, "o sujeito da experiência é um sujeito ex-posto". (LARROSA, 2002, p. 25, grifo nosso). 
Ao debruçar-se sobre a temática, este artigo não se constitui como pioneiro e nem mesmo como única produção acadêmica com ênfase em estudos sobre a homossexualidade e escola, e não se pretende solilóquio. Diante de estudos feitos por Fernando Seffner (2009), Rogério Junqueria $(2009,2013,2015)$ e Anderson Ferrari (2014) se têm atentado para a relação entre homossexualidade e escola, mais especificamente a relação homossexualidade masculina e ambiente escolar. Ademais, de acordo com Ferrari (2014), as produções midiáticas que vem sendo produzidas na atualidade mostram que a homossexualidade é um assunto que vem sendo tratado, portanto, ele não pode ser negado, negligenciado, mesmo que existam movimentos que tentem silenciar os debates.

A escola se volta para aquele/a que melhor busca ser o modelo comportamental daquilo que "deve" ser seguido. Todavia, sabe-se que existem diferenças e que cada um/uma tem suas particularidades, suas marcas nos corpos e que nem sempre essas diferenças são entendidas como positivas, mas ao contrário, são a partir delas que o sujeito se torna alvo de correções, constante vigia; se torna um corpo que precisa ser governado, gerenciado e corrigido. (FOUCAULT, 2010).

Assim, é partindo destas discussões e pressupostos que serão construídas as análises dos livros.

\section{Experiências gays e a escola}

Nesta seção, serão apresentadas análises juntamente às narrativas que foram retiradas dos artefatos culturais. As narrativas dizem respeito às personagens Aristóteles e Dante (Livro 1$)^{4}$, Will e Will (Livro 2$)^{5}$ e Paul e Tony (Livro 3$)^{6}$.

As narrativas apontam para visões diferentes acerca da escola, pois cada personagem se mostra em diversos contextos e pertencem a livros diferentes, no entanto, é possível observar o entendimento de escola enquanto uma instituição que causa desconforto nas personagens. Paul (Livro 3) cria uma aliança para unir forças contra algum tipo de preconceito e, mais do que isso, se "alia" aos/às heterossexuais que não o discriminam por conta de sua sexualidade. Aristóteles (Livro 1) se mostra relutante em ir para uma escola onde só há meninos, isso porque, ao longo da narrativa, ele afirma que nunca se sentiu bem na companhia de outros garotos, como vê na cena a seguir "meu

\footnotetext{
${ }^{4}$ Livro Aristóteles e Dante descobrem os segredos do universo.

${ }^{5}$ Livro Will \& Will um nome, um destino.

${ }^{6}$ Livro Garoto encontra Garoto.
} 
problema com garotos é que eu não fazia a menor questão de ficar perto deles. Quer dizer, me causavam desconforto. Não sei por quê, exatamente." (Trecho do Livro 1, p. 25). Will (Livro 2), quando fala de coisas das quais gostaria de fugir, menciona a escola como uma delas. O que é possível notar é o fato de que as personagens não se veem como figuras que estivessem integradas às rotinas escolares, vê-se que se sentem como uma espécie de estranho, em especial nas falas de Will e Aristóteles. Para Louro (2000, p. 60), "os processos de escolarização sempre estiveram - e ainda estão - preocupados em vigiar, controlar, modelar, corrigir, construir os corpos de meninos e meninas, de jovens homens e mulheres". Essa busca por controlar e modelar sujeitos e seus corpos nem sempre de fato os controlam, mas acabam contribuindo para que os sujeitos não se vejam como parte da escola. Uma experiência de não pertencimento.

Nesse aspecto, nota-se que os sujeitos personagens (caso de Will - Livro 2 e Aristóteles - Livro 1) foram interpelados por acontecidos escolares que acabaram por proporcionar uma visão negativa da instituição, algo que lhes causa desassossego. Nisso, vê-se que esta forma de compreender a escola se configura como uma experiência, com base no princípio da exterioridade (LARROSA, 2011), tendo em vista que os acontecimentos que lhes impulsionaram estes sentimentos em relação à escola são estranhos às personagens - situações como os atos que os ridicularizam por conta da sua sexualidade e mesmo a exclusão por conta dela -, isso porque "a experiência é algo que acontece com a pessoa, mas algo que lhe é estranho e que dela não faz parte" (GARCIA, 2015, p. 78). Assim, compreender-se como um "não pertencente" a escola, não é uma experiência que esteja no próprio sujeito, mas que fatores da rotina escolar os fazem experenciar a marginalização.

A marginalização de alguns sujeitos se dá pela existência de uma identidade hegemônica que faz com que as outras sejam vistas como anormais. Ao idealizar a figura de um/uma aluno/a "padrão", a escola captura aquele/a dito/a anormal para então normalizá-lo/a; para o pesquisador queer Miskolci (2013, p. 40), "historicamente, a escola foi durante muito tempo um local de normalização, um grande veículo de normalização estatal". Por vezes, ela reforça discursos naturalizados socialmente, deixando de lado a possibilidade de colocar em xeque algumas verdades culturais, tal como propõe preceitos da Teoria Queer: a escola precisa ser um espaço em que o "naturalizado e tido como incontornável pode ser confrontado por pedagogias dispostas a promover diálogos,

\footnotetext{
${ }^{7}$ Os trechos grifados dizem respeito ao material de análise.
} 
releituras, reelaborações e modos de ser, ver, classificar e agir mais abertos e criativos". (JUNQUEIRA, 2013, p. 494).

Ao corroborar com as palavras de Junqueira (2013), acredita-se que a escola pode e deve ser um espaço em que novas formas de conviver são pensadas. É o caso de Paul (Livro 3), que vê as diferenças como produtivas, oportunidades de estabelecer novos laços, "No sexto ano, Cody, Joni, uma garota lésbica do quarto ano chamada Laura e eu formamos a primeira aliança gay-hétero de nossa escola de ensino fundamental." (Trecho do Livro 3, p. 22). Tal colocação mostra que é possível potencializar as diferenças, tornálas uma fonte de aprendizado.

Porém, há uma representação de modos de ser gay e modos de ser heterossexuais: o gay como aquele que entende de moda e festas, como Paul. Leandro Colling (2007), ao falar sobre a representação de personagens gays na telenovela, evidencia que alguns/algumas autores/as escolhem criar personagens gays mais caricaturados na intencionalidade de fazer com que o/a telespectador/a identifique rapidamente quem é a personagem gay.

Nesta esteira, as práticas escolares e o cotidiano escolar, muitas vezes ao invés de promover desnaturalizações, acabam por legitimá-las. Por conseguinte, a escola se torna uma tecnologia de gênero e sexualidade que necessita ser questionada e repensada. (MISKOLCI, 2013).

Semelhante a Tiny Cooper (Livro 2), Paul (Livro 3) também tem destaque na escola por conta de produções artísticas, pela personalidade e pelo fato de se dar bem com boa parte dos colegas; Dante (Livro 1) também é um jovem bem-quisto na escola, por alguns. Os três não possuem problemas quanto a sua sexualidade, apenas Dante teme contar para os pais, mas as outras personagens não passam pelo momento de "assumir-se" homossexual durante a narrativa. Ao assumirmos certas marcas identitárias, sejam de gênero, sexualidade e tantas outras, somos categorizados/as socialmente como sujeitos normais ou anormais; somos vistas/os como exemplo a ser seguido ou nos tornamos fortemente foco das estratégias de normalização. (FOUCAULT, 2010). Colocar-se socialmente como gay também proporciona experiências.

O sujeito da experiência, segundo Larrosa (2002), passivo, exposto aos acontecimentos, um sujeito de paixão, é resultado de suas experiências que não somente deixam rastros, mas nos constituem, pois é "o que nos faz como somos, que transforma o que somos e o que converte em outra coisa" (LARROSA, 2015, p. 48), nota-se que a forma 
como as personagens constroem os entendimentos sobre si é atravessada pelos acontecimentos que lhes acontecem, pelos sentidos que dão a esses acontecimentos.

Nesse sentido, vê-se que a forma como Dante (Livro 1) e Paul (Livro 2) vivem e tomam para si a experiência homossexual faz com que suas compreensões sobre si sejam representadas de maneira positiva. Com isso, não se quer dizer que essas personagens - e mesmo pessoas gays - não enfrentam situações de preconceito no seu cotidiano ao se colocarem socialmente como homossexuais, porém, sinaliza que o entendimento sobre a homossexualidade que não está pautado na abjeção contribui para uma maior aceitação de si e de outros/as.

Diferente das personagens listadas, Aristóteles (Livro 1), Will (Livro 2) e Tony (Livro 3) são mais retraídos, não aceitam facilmente sua sexualidade: Tony por conta de seus pais, Will e Aristóteles por conta dos significados e estigmas que o preconceito provoca. Os três não possuem uma visão confortável acerca da escola, nem mesmo sobre si. Nesta esteira, nota-se que as formas como a escola produz a experiência homossexual é um dos fatores fundamentais no processo de atribuição de sentido e significado acerca da homossexualidade. Com isso, defende-se que a escola precisa deixar de ser uma instituição que trabalha a serviço de "tecnologias sociais que buscam enquadrar cada um em uma identidade, adequar cada corpo a um único gênero" (MISKOLCI, 2013, p. 11), tendo em vista que ela também interpela a forma como o sujeito gay olha para si e, principalmente, a forma como a sociedade os olha.

Nesse sentido, a experiência homossexual é balizada pela instituição escolar, posto que a forma como a escola lida com a homossexualidade acaba por caracterizar a experiência homossexual como algo socialmente aceitável ou não.

A experiência já não é o que nos acontece e o modo como lhe atribuímos ou não um sentido, mas o modo como o mundo nos mostra sua cara legível, a série de regularidades a partir das quais podemos conhecer a verdade do que são as coisas e dominá-las. (LARROSA, 2002, p. 28).

Vê-se que escola é representada ora como espaço de combate às diversas formas de preconceito e ora como uma instituição que protagoniza processos de exclusão. Sendo assim, corrobora-se que os mais variados tipos de preconceitos são conjunturas da rotina escolar (JUNQUEIRA, 2015). Portanto, não são elementos exteriores dessa, mas constituintes dela, tendo em vista que trabalham na manutenção da exclusão de alguns/algumas e hegemonia de outros/as. 
Percebe-se que os livros possibilitam a discussão do caráter compulsório de uma heterossexualização dos sujeitos (JUNQUEIRA, 2013) através de classificações, hierarquizações, e ao ridicularizar homossexuais, como é o caso da professora de Paul (Livro 3), ao afirmar que "é gay sem sombra de dúvida" quando Paul ainda estava na educação infantil. Ao dizer isso tem-se um acontecimento que é exterior a Paul. Esse acontecimento faz com que ele volte para si e pense a respeito daquilo que a professora proferiu, um acontecimento marcado pelo princípio da reflexividade (LARROSA, 2011). Assim que pensa sobre, Paul produz um significado para ele sobre aquilo que lhe aconteceu, aquilo que lhe tocou, e assim, ele vivencia a experiência homossexual no contexto da escola, o que nos leva ao princípio da subjetividade. (LARROSA. op. cit.). Ou seja, ele cria um sentido próprio sobre o que é ser gay na escola. E essa experiência acaba por subjetivá-lo.

Mas, o que leva a professora a concluir isso? O que caracteriza o sujeito gay? O imaginário social naturaliza certas atitudes como do universo feminino e outras como do universo masculino, fazendo com que se antecipe certos enquadramentos sociais. Às vezes, nem mesmo o próprio sujeito se reconhece na identidade em que foi categorizado/a. Esses processos fazem com que "sujeitos ainda muito jovens podem ser alvo de sentenças que agem como dispositivos de objetivação e desqualificação: Você é gay”. (JUNQUEIRA 2015, p. 227, grifo nosso).

É nesse aspecto que se destaca a importância da escola na educação para a sexualidade, pois “é o local de problematização do senso comum, do que não nos assusta mais porque naturalizamos", conforme reforça a ideia de Ferrari, (2014, p. 106). Por essa razão, a escola precisa ser o espaço onde possamos abandonar aquela velha opinião formada sobre tudo, como nos alerta Raul Seixas. Talvez, se mais discussões e debates acontecessem, Dante (Livro 1) não seria agredido e visto como estranho, assim como Paul (Livro 2) não teria em seu boletim pré-julgamentos sobre sua sexualidade, Tony (Livro 3) não seria proibido de viver a sua sexualidade ou mesmo Will (Livro 1) não precisaria lutar pelo direito de Tiny (Livro 1) utilizar os vestiários masculinos, “depois que um membro do conselho escolar ficou todo irritado com a presença de gays no vestiário" (Livro 2, p. 9).

Lamentavelmente, a escola também é representada como instituição que cultiva, consente e legitima homofobias, preconceitos de mais variadas ordens, e esses "atuam na estruturação desse espaço e de suas práticas pedagógicas e curriculares” (JUNQUEIRA, 2015 , p. 235, grifo do autor), isso porque fabricam sujeitos por meio de regimes de 
verdade, segregações, distinções e violências. "A escola é um desses lugares e espaços em que esses jogos de verdade estão presentes e nos organizando como sujeitos de desejo" (FERRARI, 2014, p. 113), ou seja, como um lugar de interdição da sexualidade.

Além disso, nós vamos nos constituindo como sujeitos a partir dos mais variados marcadores que tomamos como nossos, ou mesmo que apontam como sendo nossos. As variadas formas de ser sujeito que construímos ao longo de nossas vidas são marcas que nos posicionam no mundo, de modo que, ao assumirmos determinadas posições, ao nos colocarmos performativamente em uma posição de sujeito, a sociedade nos enquadrará, buscando, muitas vezes, nos limitar a partir disso. (BUTLER, 2015).

Quando a professora de Paul (Livro 3) o classifica por meio da linguagem, faz com que uma leitura pessoal - e ao mesmo tempo baseada em significados sociais - haja sob o entendimento de si, categorizando a sexualidade dele; do mesmo modo que a fala da professora e a forma que expõe isso parece ignorar os processos sociais que desvalorizam a homossexualidade. De acordo Junqueira (2015, p. 232):

[...] somente um furor disciplinar heterorregulador pode fazer alguém identificar/antecipar e atribuir (como em uma sentença condenatória) homossexualidade a uma criança e não se inquietar diante da violência a que é submetida, coletiva e institucionalmente.

O constante, por vezes sutil, processo de heterossexualização dos corpos realizado por diversas instâncias sociais e instituições faz com que discursos e práticas que não se enquadram nas normas de gênero sejam entendidas como abjetas. Para Louro (2009, p. 91), “o processo de heteronormatividade não só se torna mais visível em sua ação sobre os sujeitos masculinos, como também aparece, neste caso, frequentemente associado com a homofobia". No entanto, é preciso salientar que não só o sujeito homossexual é alvo da norma, mas todos/as são interpelados/as por ela, assim como coloca o pensamento queer. (MISKOLCI, 2013).

Em algumas narrativas, também se nota que as injúrias partem de outros homens, evidenciando o fato de que quando o "macho" que busca adequar-se a um modelo hegemônico de homem viril ao desqualificar, humilhar e agredir um sujeito homossexual pensa ratificar a sua posição enquanto hegemônica, como é o caso desta narrativa "Esse cara do Grupo de Amigos, chamado Clint, estava falando sobre a carta na hora do almoço e, ao falar dela, me chamou de baitola, e eu não sabia o que era um baitola" (Trecho do Livro 2, p. 10). Ou mesmo quando Aristóteles (Livro 1) se recusa a usar drogas e é 
pejorativamente classificado como gay. A ofensa homofóbica não só demarca quem seria o abjeto, mas também "exalta" aquele que profere. Outrossim, o insulto não se dirige apenas aqueles que são gays - Will Grayson (Livro 2) é heterossexual e Aristóteles (Livro 1) neste momento da história se entendia como heterossexual -, mas também ofende e ensina aquele/a que está ao redor. A injúria também norteia a forma como eles construíram significados sobre a homossexualidade. O insulto também serve para mostrar ao outro qual sexualidade é respeitada socialmente e qual é alvo de desrespeito e infâmia, ou seja, o insulto também é pedagógico. (JUNQUEIRA, 2015).

A experiência homossexual não marca somente aquele que é gay, mas também deixa rastros naqueles que não são, isso evidencia o quanto a heterossexualidade compulsória e os preconceitos estão constantemente ao nosso redor, seja por conta de nosso desejo ou mesmo daqueles que nos cercam. É nesse sentido que a experiência homossexual é constantemente colocada à margem da sociedade. Vê-se que a homossexualidade, infelizmente, é vista como algo "ruim", que serve como xingamento, seja para sujeitos gays ou não. Por isso, é necessário "desestabilizar relações de poder, fender processos de hierarquização, perturbar classificações e questionar a produção de identidades reificadas e diferenças desigualadoras". (JUNQUEIRA, 2015, p. 236). Com base nisso, defende-se que a instituição escolar deve estar atenta à forma como as relações entre os alunos e alunas acontecem dentro do ambiente escolar, a fim de promover uma educação para a sexualidade juntamente com uma educação que promova a equidade.

\section{Por escolas de transformações}

Mais do que interpelar a maneira como os alunos veem a si mesmos, percebe-se que os discursos e as práticas que circulam no espaço da escola também produzem a forma como os alunos que não são homossexuais produzem significados sobre a homossexualidade. Em um espaço que está pautado em uma divisão de gênero e parte do pressuposto de que o normal é a heterossexualidade, qual é o espaço do gay na escola? Teria ele um espaço legítimo na escola? Ou apenas lhe cabe a marginalização?

Ao trazer temas como a homossexualidade para o contexto da literatura, em especial a produzida para jovens, coloca-se em discussão temas que outrora (e, infelizmente, ainda hoje) são vistos como promíscuos, perigosos, devassos ou mesmo imorais. Fazer com que a experiência homossexual seja posta em debate por meio destes 
livros contribui para a promoção da educação para a sexualidade. No entanto, sabe-se que somente a existência destes livros não é suficiente para que aconteçam debates e problematizações, é preciso que a escola se proponha a ser um espaço de transformação. Espera-se que a escola produza sujeitos sensíveis e abertos a transformações, que reflitam sobre suas verdades, que estejam disponíveis aos acontecimentos que lhe passam.

\section{REFERÊNCIAS}

BARBO, Daniel. A emergência da homossexualidade: cultura grega, cientificismo e engajamento. In: COSTA, Adriane Vidal; BARBO, Daniel (Orgs.). História, literatura \& homossexualidade. Belo Horizonte, MG: Fino Traço, 2013.

BUTLER, Judith. Regulações de Gênero. Cad. Pagu, n. 42, p. 249-274, 2014.

BUTLER, Judith. Sujeitos do sexo/gênero/desejo. In: BUTLER, Judith. Problemas de gênero. Rio de Janeiro: Civilização Brasileira, 2015, p. 17-58.

COLLING, Leandro. Personagens homossexuais nas telenovelas da Rede Globo: criminosos, afetados e heterossexualizados. Revista Gênero, Rio de Janeiro, v. 8, n. 8, p. 207-222, jul./dez., 2007.

COSTA, Marisa Vorraber. Currículo e Política Cultural. In: COSTA, Marisa Vorraber. (Org.). O currículo nos limiares do contemporâneo. 3 ed. Rio de Janeiro, DP\&A, 2003. p. 37-68.

FERRARI, Anderson. Experiência homossexual no contexto escolar. Educar em Revista, Curitiba, Edição Especial, n. 1, p. 101- 16, 2014.

FOUCAULT, Michael. Os anormais. 2 ed. São Paulo: Editora WMF Martins Fontes, 2010.

FOUCAULT, Michael. Verdade e Poder. In: FOUCAULT, Michael. Microfísica do poder. 3 ed. Rio de Janeiro: Paz e Terra, 2015

GARCIA, Osmar Arruda. Marcas da experiência na formação docente em gênero e diversidade sexual: um olhar sobre o curso "Gênero e Diversidade na Escola" (GDE). 2015. 162f. Dissertação (Mestrado em Educação) - Faculdade de Educação da Universidade de São Paulo, São Paulo, 2015.

JÚNIOR, Adail Sebastião Rodrigues. A representação de personagens gays na coletânea de contos Stud e em sua tradução as aventuras de um garoto de programa. Trab. Ling. Aplic., Campinas, v. 46, n. 2, p. 263-281 jul./dez,. 2007.

JUNQUEIRA, Rogério Diniz. Pedagogia do Armário: a normatividade em ação. Revista Retratos da Escola, Brasília, v. 7, n. 13, p. 481-498, jul./dez., 2013. 
JUNQUEIRA, Rogério Diniz. Temos um problema em nossa escola: um garoto afeminado demais. Pedagogia do armário e currículo em ação. Revista Educação e Políticas em Debate, Uberlândia, v. 4, n. 2, ago/dez., 2015.

LARROSA, Jorge. Experiência e alteridade em educação. Revista Reflexão e Ação, Santa Cruz do Sul, v. 19, n. 2, p.04-27, jul./dez., 2011. DOI: 10.17058/rea.v19i2.2444.

LARROSA, Jorge. Notas obre a experiência e o saber de experiência. Revista Brasileira de Educação, 2002, n. 19, p. 20-28. ISSN 1413-2478. DOI: 10.1590/S141324782002000100003.

LARROSA, Jorge. Tremores: escritos sobre experiência. Belo Horizonte: Autêntica, 2015.

LOURO, Guacira Lopes. Corpo, Identidade e Escola. Educação \& Realidade, Porto Alegre, v. 2, n. 25. p. 59-76, jun./dez., 2000.

LOURO, Guacira Lopes. Heteronormatividade e Homofobia. In: JUNQUEIRA, Rogério Diniz (Org.). Diversidade Sexual na Educação: problematizações sobre a homofobia nas escolas. Brasília: Ministério da Educação, Secretaria de Educação Continuada, Alfabetização e Diversidade, UNESCO, 2009, p. 85-94.

LOURO, Guacira Lopes. Uma política pós-identitária para a Educação. In: LOURO, Guacira Lopes. Um corpo estranho: ensaios sobre sexualidade e teoria queer. 2 ed. Belo Horizonte: Autêntica, 2013.

MISKOLCI, Richard (Org.). Marcas da Diferença no Ensino Superior. São Paulo: EdUFScar, 2014.

MISKOLCI, Richard. Teoria Queer: um aprendizado pelas diferenças. Belo Horizonte: Autêntica Editora: UFPO - Universidade Federal de Ouro Preto, 2013.

RESENDE, Beatriz. A Literatura Brasileira num mundo de fluxos. Revista do Programa Avançado de Cultural Contemporânea, Rio de Janeiro, Ano 4, n. 1, 2011.

RIPOLL, Daniela; SILVEIRA, Rosa Maria Hessel. A temática homossexual na literatura infanto-juvenil atual. In: V Congresso Internacional em Estudos Culturais, 2016, Aveiro. Atas do V Congresso Internacional em Estudos Culturais. Coimbra: Grácio Editor, 2016.

SEFFENER, Fernando. Equívocos e Armadilhas na Articulação entre Diversidade Sexual e Políticas de Inclusão Escolar. In: JUNQUEIRA, Rogério Diniz (Org.). Diversidade sexual na educação: problematizações sobre a homofobia nas escolas. Brasília: Ministério da Educação, Secretaria de Educação Continuada, Alfabetização e Diversidade, UNESCO, 2009, p. 124-139.

SILVA, Antônio de Pádua Dias.; FERNANDES, Carlos Eduardo Albuquerque. Crítica Literária ou Cultural? Caminhos críticos da literatura de temática gay. Crítica Cultural (Critic), Palhoça, v. 6, n. 1, p. 129-141, jan./jul., 2011. 
SILVA, Tomaz Tadeu da. A pedagogia como cultura, a cultura como pedagogia. In. SILVA, Tomaz Tadeu da. Documentos de identidade: uma introdução às teorias do currículo. 3.ed. Belo Horizonte: Autêntica, 2010, p. 139-142.

\section{Como citar este artigo:}

AMARAL, Caroline Amaral.; RIBEIRO, Paula Regina Costa. Literatura juvenil contemporânea: representações de experiências homossexuais na escola. Revista IberoAmericana de Estudos em Educação, Araraquara, v. 13, n. 4, p. 1726-1741, out./dez., 2018. E-ISSN: 1982-5587. DOI: 10.21723/riaee.unesp.v13.n4.out/dez.2018.10895

Submissão em: 16/01/2018

Aprovação final em: 15/05/2018 